\title{
Transcendent and Tragic Aspects of American Philosophy: Religiöse Vielfalt im amerikanischen Pragmatismus - neue Einsichten
}

\begin{abstract}
Zusammenfassung: Der Essay greift zurück auf die bereits von Wilhelm Wundt 1911 formulierte These, dass der amerikanische Pragmatismus („American Philosophy“), nur über dessen Religionsphilosophie voll zu verstehen sei. Wer dieser Aussage nachgeht, entdeckt bei den Gründungsvätern des Pragmatismus eine beeindruckende Vielfalt religiöser Standpunkte mit modernem Habitus. Für eine im Säkularisierungsprozess fortschreitende Gesellschaft ergeben sich daraus heute bedenkenswerte Einsichten. Einige dieser Einsichten sind tragisch, weil sie Probleme unserer Zeit betreffen, die „pragmatisch“ nicht zu lösen sind.
\end{abstract}

Schlüsselwörter: Pragmatismus, Religion, Transzendenz, American Philosophy

Summary: This essay builds on Wilhelm Wundt's thesis from 1911that American pragmatism („American philosophy") can only be understood through its religious philosophy. When examining this claim more closely, one can discover an impressive multiplicity of religious perspectives with a modern habitus among the founding fathers of pragmatism. They generate insights worthy of consideration for contemporary societies advancing in secular processes. Some of these insights are tragic because they concern problems of our time that cannot be solved „pragmatically".

Keywords: pragmatism, religion, transcendence, American philosophy

Резюме (Хайн Реттер: Трансцендентные и трагичные аспекты американской философии: религиозное многобразие в американском прагматизме - новое понимание): Статья обращается к тезису, сформулированному Вильгельмом Вундтом еще в 1911 году, о том, что американский прагматизм («американская философия») можно полностью понять лишь через его религиозную философию. Кто следует данному положению, тот открывает у отцов-основателей прагматизма впечатляющее разнообразие религиозных точек зрения с современными формами. Для общества, находящегося в процессе секуляризации, проистекают сегодня из этого поводы для нового понимания. Некоторые из них являются трагичными, потому что они касаются проблем нашего времени, которые нельзя решить «прагматически».

Ключевые слова: прагматизм, религия, трансцендентность, американская философия

\section{Einführung}

„The Varieties of Transcendence. Pragmatism and the Theory of Religion“ lautet der Titel eines 2016 in den USA erschienenen Sammelbandes - das Ergebnis einer deutsch-amerikanischen Kooperation. Die Beiträge des Bandes erschließen die religiösen Bindungen der Philosophen des klassischen Pragmatismus der Zeit nach 1900 in ihrer Vielgestaltigkeit (Deuser et al., 2016). Ursprünglich ging es darum, diesen Band - im Folgenden „Rezensionsband“ genannt - durch eine Buchbesprechung zu würdigen. Am Ende wurde daraus ein über die Rezensionsabsicht weit hinausführender Text. 
Mit dem bereits genannten Buchtitel erinnern die Herausgeber unseres Rezensionsbandes offensichtlich an James' religionspsychologisches Hauptwerk („The Varieties of Religious Experience“) von 1902. Die 14 Fachbeiträge ${ }^{1}$ des hier im Mittelpunkt stehenden Buches gehen zurück auf eine internationale Tagung, die vom 16. bis 18. Februar 2012 am Max Weber-Kolleg für kultur- und sozialwissenschaftliche Studien der Universität Erfurt stattfand. Zu Wort kommen führende amerikanische und europäische (in der Mehrzahl deutsche) Experten - Philosophen, Theologen, Geisteswissenschaftler -, die seit vielen Jahren durch ihre Veröffentlichungen einerseits als profunde Kenner des amerikanischen Pragmatismus ausgewiesen sind, andererseits dabei besonders die Rolle der Religion, der Ethik und der Werte im Denken der Gründergestalten dieser vor und nach 1900 in den USA sich ausbildenden Denkrichtung im Blick haben. Dass das Thema „Pragmatismus und Religion“ in der internationalen Religionsphilosophie weiterhin bedeutsam bleibt, zeigt auch das 2014 erschienene Buch von Michael R. Slater (2014), der an der Georgetown University (Washington D.C.) lehrt.

\section{Umrisse einer pragmatischen Phänomenologie der Religion}

Den Anfang in der Reihenfolge der Beiträge im Rezensionsband bildet Christoph Seiberts Erörterung des amerikanischen Pragmatismus und dessen Methodenbewusstsein. Sie sind auch bedeutsam für die Religionsphilosophie der Gegenwart. Die zu Grunde liegende These lautet: Die moderne, erfahrungsoffene Religionsphilosophie hat durch die anhaltende Rezeption des Pragmatismus ein geschärftes Methodenbewusstsein gewonnen. Seibert, Hamburger Theologe, dessen Tübinger Habilitationsschrift ihn als derzeit bedeutendsten James-Interpreten ausweist, macht mit seinem Text deutlich, dass moderne Religionsphilosophie heute ohne ein methodisch kontrolliertes Vorgehen nicht auskommt. Wenn dabei der Pragmatismus Pate stehen soll, ist klar, dass es nicht um spekulatives Nachdenken, sondern um empirisches Vordenken geht. Man hat sich zu vergegenwärtigen, sagt Seibert, dass Forschung keinen Nullpunkt besitzt. Vorlaufende Kontexte sind in der zu erfassenden Realität wie in den Texten der Fachliteratur vom Interpreten zu prüfen. Die gilt im Grunde für jede Interpretation. Doch in der Religionsphilosophie verdient die Forderung besondere Beachtung. Seibert plädiert dafür, religionsphilosophische Studien nicht einer methodischen Engführung zu unterziehen, sondern den Anfang der Reflexion durchaus breit zu wählen; Ausscheidungsprozesse können später erfolgen. Bei den vorgestellten Gesichtspunkten greift Seibert im Wesentlichen auf James zurück.

Rationale empirische Analyse von „Religion“ meint die Erfassung der religiösen Anschauungen einer bestimmten Zeit, einer bestimmten Bevölkerung, Gruppe, Denomination, um sie dem wissenschaftlichen Rekonstruktionsprozess zu unterziehen. Nicht selten geschieht dies in vergleichender Absicht. Seibert erörtert die Schwierigkeit, dass die Rationalität der Methode quer stehe zu nicht-rationalen Glaubensbefunden, ethischen und ästhetischen Gesichtspunkten, religiösem Erleben und religiöser Symbolik. Die Sphäre des Nichtrationalen - aber deshalb doch keineswegs Irrationalen - zu erfassen sei notwendig, um das Ganze in den Blick zu bekommen, betont Seibert. Das könnte, so ein eigener hinzugefügter Gedanke, von besonderem Interesse sein, wenn es im Sinne von „reconstruction“, darum geht, in der Reflexion vorgefundener Religiosität etwas freizulegen, das zeitweise verschüttet war. Rationales Konstruieren einerseits und phänomenologische Schau andererseits setzen differente Akzente. Seibert behandelt beide Aspekte als methodische Stufen, die jeweils weitere Differenzierung erfahren. Die erste Stufe, "Construing Religion“, hat sowohl die historische Gewordenheit der vorgefundenen religiösen Anschauung(en) zu verfolgen als auch das situative Umfeld zu beachten, das sich der Forscher (zum Beispiel im Fall von Feldforschung) erschließen muss. Seibert gibt zu bedenken, dass die situative Ge- 
bundenheit des Forschers jene im (natur-) wissenschaftlichen Vorgehen selbstverständliche Forderung nach Neutralität (Ausschaltung alles Subjektiven als Störfaktor) im empirischen religionsphilosophischen Forschungsprozess nicht immer die beste Option darstelle. Forschung sei in der Religionsphilosophie vor allem hermeneutische Teilhabe. Doch dahinter verbirgt sich natürlich ein methodisches Basisproblem, das nicht weiter diskutiert wird: Wie gewinnt Forschung einen höheren Geltungsanspruch, wenn sie über die Erfassung subjektiver Befindlichkeiten nicht hinauszugehen vermag?

Seibert sieht die zweite Stufe des pragmatisch orientierten religionsphilosophischen Forschungsprozesses in einem Vorgehen, das er als „Elaborating on the Meaning of Religious Ideas“ bezeichnet. Hier geht es um den konkreten, in der Lebenswelt verankerten Glauben und die mit ihm verbundenen Sinnhorizonte, die in ihrer Vielfalt phänomenologisch zu erschließen sind. Mit dem bemerkenswerten Statement, dass religiöse Überzeugungen in Glaubenshaltungen ruhen, die dem Menschen Sicherheit geben in dem, was er zu erwarten hat, schließt der Autor seinen angenehm kurzen, inhaltlich dementsprechend prall gefüllten Beitrag. Was lässt sich aus ihm folgern? Formuliert man Seiberts Statement um zur Frage: „Was darf ich erwarten?“ kommt man an Immanuel Kant nicht vorbei. Der von James nicht gerade geliebte Königsberger Kollege formulierte im 18. Jahrhundert bekanntlich vier Fragen, die seine Philosophie zu beantworten suchte. Kants dritte Frage betraf die Religion und lautete: Was darf ich hoffen? Sehr viel anderes, als auf diese Frage eine befriedigende Antwort zu finden, leistete auch die Religionsphilosophie der Pragmatisten nicht.

Seiberts Analyse ist außerordentlich verdienstvoll. Sie macht einer methodisch geschulten Leserschaft allerdings auch einen Sachverhalt deutlich, der unerwähnt bleibt: Dass die Forschungsansätze der frühen Pragmatisten aus heutiger Sicht nicht als Vorstufen, sondern als Sonderwege qualitativer Forschung zu sehen sind gegenüber den Standards qualitativer und quantitativer empirischer sozialwissenschaftlicher Methoden. Deren Einsatz ist seit langem üblich - nicht zuletzt in der Religionsforschung der USA, wie sie etwa in den Studien von Edwin D. Starbuck oder James H. Leuba in der Hoch-Zeit des frühen Pragmatismus um 1900 begannen und auch sogleich zu einem Methodenstreit führten. Seibert erwähnte beide Forscher in seiner Habilschrift über James. Welche methodischen Ideen der frühen Pragmatisten die heutigen Standards empirischer Forschung in den Religionswissenschaften prägen, steht außerhalb des Beitrages. Es lohnt sich, Methoden der Religionsphilosophie weiter zu diskutieren.

Das Thema empirisch-pragmatische Religionsphilosophie, das Seibert phänomenologisch erschließt, erhält seine inhaltliche Fortführung im letzten Beitrag des Bandes durch Robert C. Neville. Er entfaltet eine auf den klassischen Pragmatismus zurückgreifende Theorie der Religion. Im Hintergrund steht die dreibändige „Philosophical Theology“ Nevilles. Hier wird durch eine Phänomenologie der reflektierten Letztmöglichkeiten von Erfahrung, die im menschlichen Leben eine Rolle spielen, religiöse Tiefe spürbar. Es geht Neville um die letzten Dinge, wie sie in das Bewusstsein jedes Einzelnen in einer lebenswichtigen Situation treten: Welche Reaktionsmuster beinhaltet die Erfahrung von „Letztheit" (ultimacy)? Es sind existenzielle Grenzsituationen, in denen kognitive Antworten, Verhaltensmuster, Identifikationen, Lebensweisen und Leitlinien der Lebensführung wachgerufen werden. Ihre Erfassung steht nach Neville im Zentrum der philosophischen Theologie. Angesichts der Vielheit der zu erfassenden Phänomene in ihrem Erlebniskontext ist die Aufgabe des Forschers gewaltig. Neville versucht, durch bestimmte Schlüsselbegriffe das zu bearbeitende Feld der Phänomene zu ordnen.

Religiös zu leben bedeutet nach Neville einer „sacred worldview“ zu folgen, die von einer nichtreligiösen Sicht der Dinge unterschieden wird. Dabei wird zugestanden, dass beide Begriffe - „religiös“ wie „nicht-religiös“ - eine Fülle von Varietäten unter sich begreifen und ein breites Übergangsfeld besit- 
zen. Neville macht in diesem Kontext auf den fließenden Charakter des Religiösen im Lebensvollzug aufmerksam, der dazu führt, sowohl „daheim“, als auch „immer unterwegs“ zu sein.

Der Situationsbegriff bildet den Ausgangspunkt für die phänomenologische Analyse. Darin sieht sich Neville einig mit Paul Tillich. Er erwähnt dessen Band „Die religiöse Lage der Gegenwart“ von 1926 bzw. dessen Übersetzung von 1932 mit dem Titel: „The Religious Situation“. Man kann hinzufügen: Ein Jahr früher erschien in der Krisenzeit der Weimarer Republik der Essay „Die geistige Situation der Zeit“ von Karl Jaspers. Ohne dass die Gründungsväter des amerikanischen Pragmatismus dem Beachtung schenkten, war in der deutschen Philosophie nach der Jahrhundertwende dem Situationsbegriff ein breit gefächertes konzeptionelles Interesse entgegengebracht worden. Selbst über den Einschnitt des Ersten Weltkrieges hinweg blieb dieses Interesse bestehen, angefangen von der Phänomenologie Husserls über die Lebensphilosophie Diltheys bis zur Existenzphilosophie Heideggers und Jaspers'. Der von Kurt Lewin entwickelte Feldbegriff und das von Peter Petersen entwickelte, Jaspers' Begriff der „Grenzsituation“ aufnehmende Konzept der „pädagogischen Situation“ haben den Situationsbegriff auch in Psychologie und Erziehungswissenschaft Eingang finden lassen. Diese Einflüsse aufnehmend, könnte der Situationsbegriff, der in Deweys Spätwerk von 1938, „Logik. Theorie der Forschung“ eine Rolle spielt, auch für die Phänomenologie des Religiösen von Bedeutung sein.

\section{Philosophen des Pragmatismus und die Vielfalt ihrer religiösen Stand- punkte}

Fragt man, welcher Gründergestalt des Pragmatismus im Rezensionsband die größte Aufmerksamkeit geschenkt wird, ergibt sich Folgendes: William James widmen sich sechs Beiträge, zu Charles Peirce und John Dewey wird in jeweils vier Beiträgen, zu Josiah Royce in zwei Beiträgen Stellung genommen. Royces Religionsphilosophie erhält ihr Profil durch Vergleiche mit den Auffassungen von James. Als Vertreter des Neopragmatismus kommt Hilary Putnam mit einem Beitrag zu Wort, in welchem Dewey eine Rolle spielt. Dass die Religionsauffassungen von George Herbert Mead und Ferdinand Canning Scott Schiller nicht durch eigene Abhandlungen gewürdigt werden, ist bedauerlich. Das böte die Chance, bislang unbearbeiteten Boden urbar zu machen. Zwischen den Zeilen deutet ein Mead-kundiger Autor an, dass da nichts zu holen sei. Doch für eine Religionsphilosophie, die im Zeichen der Auflösung tradierter religiöser Strukturen die Übergänge zwischen weltimmanenter und transzendenter Befindlichkeit auslotet, ist Mead durchaus interessant, worauf zuerst Thomas V. Smith verwies (vgl. Smith, 1932). F.C.S. Schiller, der in Oxford lehrte, bevor er endgültig in den USA verblieb, behandelte das Verhältnis von Pragmatismus und Religion durchaus ausführlich (vgl. Schiller, 1907).

Die Charles S. Peirce gewidmeten Beiträge des Rezensionsbandes betreffen mehrere Aspekte. Zum einen geht es um die religiös fundierte Zeichenlehre (Semiotik) von Peirce, für die Michael L. Raposa den Begriff „Theosemiotic“ prägte, zum andern wird das Verhältnis zwischen individueller und sozialer Dimension bei Peirce erörtert. Das leistet Gesche Linde gekonnt. Vincent Colapietro schließt daran an, um weitere Aspekte im Denken von Peirce hervorzuheben, die ihn paradoxerweise nicht wie üblich als Gründervater, sondern als „dissenting voice“ im klassischen Pragmatismus erscheinen lassen: so wenn Peirces Interesse an Shakespeare erörtert wird. Als Theologe stellt Hermann Deuser = die Frage, ob bei Peirce eher von pragmatischer oder besser von pragmatizistischer Religionstheorie zu sprechen sei. Deuser bejaht Letzteres. In der Tat: Peirces Text von 1908, „A Neglected Argument for the Reality of 
God“ (Peirce, 1965, S. 311ff.) offenbart den Kern seiner religiösen Überzeugung. Zugleich bildet dieser Text das religionsphilosophische Fundament der Peirceschen Semiotik.

Der fromme Gottesglaube ist in ursprünglich christlich geprägten Kulturen heute längst nicht mehr so vorfindbar wie vor 120 Jahren. In Regionen, wo Glaubensgewissheit noch anzutreffen sein mag, hat sie durch die zeitintensiven Alltagsroutinen des modernen Lebens an Intensität verloren. Davon ist in den späten Texten von Peirce nichts zu spüren, wie Deusers Ausführungen zeigen. Raposas Beitrag über die Beziehung Peirces zur Philosophie von Johannes Duns Scotus, dem mittelalterlichen Philosophen, macht die tiefe Religiosität von Peirce ebenfalls deutlich. Die Gedankenführung Deusers setzt die umfangreiche Kenntnis der Religionsphilosophie Peirces und die mit ihr verwobene kategoriale Semiotik voraus. Zu deren Erschließung leistete Deuser, heute führend in der Peirce-Forschung, 1995 durch Sammlung und Übersetzung der religionsphilosophischen Texte von Peirce Maßgebliches. Peirce macht in seiner drei-relationalen Kategorienlehre sowohl den (christlich-) personalen Gott als auch das Universum in gewisser Weise verstehbar. Primäre Qualitäten, religiöse Gefühle, Anmutungen, „instinktive“ Begriffsbildungen als auch die den Kategorien zugeordneten Schlussformen gehen in Peirces Forschungslogik ein, die es ermöglicht, religiöse „Erstheit“ in der kreativen Freiheit von „musement" (Peirce) zu kommunizieren.

Die vitale Gotteserfahrung ist als subjektive Gewissheit nicht in die Form objektiv gültiger Realität überführbar. Gottesbeweise sind, wie Kant zeigte, weder empirisch noch formallogisch möglich, was nicht heißt, dass die Annahme der Existenz einer höchsten Macht als unvernünftig zu gelten habe - im Gegenteil. Geht man jedoch davon aus, dass es für den Pragmatisten unsinnig, ja unmoralisch ist, von Wahrheit zu sprechen, wenn sie nicht verifizierbar ist, dann ergibt sich ein Dilemma. Versuchte Peirce mit dem unvollständigen Schluss der „Abduktion“ einen „unvollständigen“ Gottesbeweis einzuführen? In dieser Schärfe stellt Deuser die Frage nicht - wohl weil man sie verneinen müsste. Viel mehr macht er deutlich, in welchem Ausmaß Peirce auch in seinen logischen Überlegungen einem „instinktiven“ Gottesverständnis nahe steht.

\section{Religionsphilosophie und Gesellschaftskritik}

William James ist im Rezensionsband allgegenwärtig. Sami Philström, der bedeutende Religionsphilosoph Finnlands, der 2007 auch eine Studie über die Rezeption des klassischen Pragmatismus in den nordischen Ländern veröffentlichte (online erreichbar), wendet sich den „tragischen“ Aspekten der Religionsphilosophie James' zu. Religionsphilosophie hat in der Tat die Frage zu klären, wie der Pragmatismus das Böse, das Leiden der Menschen und die Theodizee reflektierte: Wie kommt das Böse in die Welt, wenn die Schöpfung nach biblischer Aussage von Gott als „sehr gut" bezeichnet wurde? Die Erfolgsmethode des Pragmatismus besteht oft darin, Unerwünschtes einfach wegzulassen. James würde unglaubwürdig erscheinen, wenn seine Philosophie mit der Botschaft des Guten, die im Vordergrund steht, nicht auch eine Dimension besitzt, die um das Böse (the evil) in der Welt weiß, um mit der Zurückweisung des Absoluten bereit zu sein, daraus resultierende schmerzvolle Konsequenzen in Kauf zu nehmen. Philström erinnert an James' Typus des mental gesunden (healthy-minded) Menschen, der glücklich ist, indem er sein Leben in Übereinstimmung mit der Religion führen kann. Ihm lassen sich Menschen mit einer kranken Seele (sick soul) gegenüberstellen, deren Leben durch Angst, Verzweiflung, Melancholie zu zerbrechen droht. Doch was hat menschliches Leid, zumal unverschuldetes, mit der unterstellten Tragik des Jamesschen Pragmatismus zu tun? 
Die gesellschaftskritische Antwort, die sowohl Philström als auch andere Autoren eher nicht zu geben bereit sind, müsste lauten: Es ist tragisch, dass die pragmatischen Religionsphilosophen der Vielfalt des Religiösen Beachtung schenkten, indem sie vermieden, die Tiefe des gesellschaftlichen Risses und des rassischen Unrechts, in den USA zu erwähnen - nicht zu sprechen von den Lynchmorden. Die Afroamerikaner ausgrenzende und benachteiligende sogenannte Jim Crow Gesetzgebung ab den 1880er Jahren erstreckte sich bis ins Jahr 1965. Ihre verdeckte Weiterführung in der Gegenwart haben Kritiker schon längst zum Thema gemacht (Alexander, 2010). Die afroamerikanische Parallelgesellschaft, die mit dem Stigma der "Color-Line“ (W.E.B. Du Bois) lebte, wurde den frühen Pragmatisten Peirce, James und Dewey - alles erklärte Verfechter der demokratischen Werte Amerikas - nie zum Anlass, durch Einsatz der neuen Philosophie rassische Benachteiligung zu mindern. Royce (1908) war der einzige dem Pragmatismus zugewandte Philosoph nach 1900, der sich dem Problem stellte und Lösungsvorschläge diskutierte. Die gegen Schwarze gerichtete Gewalt des weißen Mobs hatte zu diesem Zeitpunkt bereits den Norden der USA erreicht. Mit der 1905 gegründeten Niagara-Bewegung formierte sich erstmals eine organisierte schwarze Bürgerrechtsbewegung. Die von Sklaverei „Befreiten“, die, als gesellschaftlich zweitklassig behandelt, so frei nicht waren, suchten Zuflucht bei ihrer Religion und ihrem eigenen Pragmatismus, um weißer Willkür und Gewaltbereitschaft möglichst zu entgehen.

Das Thema ist bis heute aktuell geblieben. Jacquelyn Ann K. Kegley (2009) betont, dass Royce im Gegensatz zu Dewey und anderen Pragmatisten das Thema Rassismus nicht verdrängte. Man fragt sich: Wie lesen heute afroamerikanische Religionsphilosophen den Erfurter Tagungsband? Die Betrachtung der Religionsphilosophie des Pragmatismus auf dem Hintergrund zeithistorischer Konflikte liegt außerhalb der Intention des Buches. Einer solchen Absicht zu folgen war vor mehr als hundert Jahren an amerikanischen Universitäten in der Tat nicht üblich. Im Vordergrund des Interesses standen damals „weißer" Pragmatismus und „weiße“ Religion; der Rezensionsband zeigt, dass das heute offenbar nicht so viel anders ist. Andererseits steht einem Austausch mit afroamerikanischen Pragmatismusforschern in Fortführung der Diskussion nichts im Weg - und ist forschungsrelevant. Sozialgeschichte, Erziehung, Bildung und Erarbeitung von Lebenschancen in Amerika seit dem Ende des Bürgerkrieges 1865 sehen aus afroamerikanischer Sicht anders aus, als „weiße“ Geschichtsschreibung dies darstellt. Afroamerikanischer Pragmatismus ist nicht selten mit religiös fundierter Trauer vermischt. Das zeigte 1903 das Buch „The Souls of Black Folk“ von W.E.B. Du Bois (deutsch: 2008), und das zeigte vor einem knappen Jahrzehnt Eduard S. Glaude jr. mit dem Buch „A Shade of Blue. Pragmatism and the Politics of Black America“.

Sami Philström kommt im Rezensionsband das Verdienst zu, ausgelotet zu haben, an welchen Stellen die gute Botschaft der Jamesschen Philosophie umschlägt in Zweifel und Nachdenklichkeit. Unter Einbeziehung anderer Denker wie Ludwig Wittgenstein und Gabriel Marcel sieht Philström in James' unbedingter Anerkennung menschlichen Leids als Realität (James selbst wurde von Depressionen und chronischen Schmerzen heimgesucht), den ersten Schritt, sich der tragischen Aspekte des Lebens bewusst zu sein. Viele Menschen erfahren kein Happy End ihres Lebens. Umso mehr forderte James eine moralische Haltung, die den leidenden Mitmenschen wahrnimmt, Mitleid in Handeln umsetzt, hilft. James meinte, dass eine Religion umso wertvoller und elaborierter sei, je mehr sie Leid und Entsagung ernst nimmt, wie dies im Christentum und im Buddhismus der Fall sei.

Über die Rolle des Pragmatismus im Hinblick auf die Tragik des Lebens philosophierte erstmals der Dewey-Schüler Sidney Hook, und zwar 1959 - hundert Jahre nach Deweys Geburt - als das Licht des Pragmatismus tragischerweise auf den Foren der US-Philosophen zu erlöschen drohte. Die USA litten 
zu diesem Zeitpunkt nicht nur an der McCarty-Ära, sondern auch am Sputnik-Schock, der die Erziehungsphilosophie Deweys (†1952) zur Projektionsfläche nationalen Versagens machte. Hook forderte vom Pragmatismus ein neues Nachdenken über Tod, Freiheit und Überleben des Menschen. Sein Essay über das Tragische ist auch heute noch beeindruckend. Dennoch erreichte Hook damit nicht jene Ebene des sozialen Protests, der die Bürgerrechtsbewegung der sechziger Jahre schuf. Dewey spielte hier erst recht keine Rolle. Doch es war Deweys Leistung vorangegangener Jahrzehnte das, was man aus europäischer Sicht zusammenfassend Pragmatismus nannte, als tragfähige Philosophie mit weltweitem Einfluss ausgewiesen zu haben.

\section{Die ideelle Sphäre, das Böse und das Verschwinden Gottes}

Victor Kestenbaum publizierte 2002 das Buch „The Grace and the Severity of the Ideal. John Dewey and the Transcendent". Mit ihm vertrat er die These, dass die wertvollsten Aussagen Deweys dort zu finden seien, wo sie quer stehen zu seinem (platt getretenen) Instrumentalismus, Pragmatismus und Naturalismus. Im Essay „Ontological Faith in Dewey's Religious Idealism“ unseres Rezensionsbandes bekräftigt Kestenbaum, dass Deweys Philosophie sehr wohl einen substanziellen Bezug zur Transzendenz besitze. Sich an Selbstbekenntnisse Deweys haltend, folgten viele Interpreten der These, Dewey sei jedem Supernaturalismus abhold. Kestenberg nötigt zu einer anderen Sichtweise, die gut tut, weil sie Interpretationsspielräume verbreitert. Doch damit wird nicht das Ganze der Deweyschen Philosophie, sondern nur ein bestimmter Aspekt betrachtet, den Kestenbaum wie mit einem Vergrößerungsglas heraushebt. Aufs Ganze gesehen, würde man Dewey jedenfalls nicht gerecht werden, ihn in die Nähe des tradierten Transzendenzbegriffs zu rücken (vgl. Ralston, 2007).

Transzendenz wird alltagssprachlich verstanden als das Vorhandensein einer Macht oder Sphäre, die jedem Zugriff entzogen ist, jedoch „Fenster“ besitzt, die existenziell berühren und kommunikative Bedürfnisse auslösen. Der Monotheismus sichert der transzendenten Sphäre eine Wirkung zu, die außerhalb des Glaubens nicht wahrnehmbar ist. Philosophiehistorisch ist Transzendenz sehr viel weiter zu verstehen als Gottesglaube: Transzendenz bildet den Gegensatz zu Immanenz. Das meint: Es existieren Dinge, Seinsqualitäten, Handlungen, Vorstellungen, die nicht allein für sich stehen (immanent sind), sondern über sich selbst hinaus verweisen auf ein höheres Anderes. Ob dieses Höhere „Gott“, „Ideal“ oder das „Absolute“ heißt, spielt zunächst keine Rolle.

Dieser Aspekt ist es, den Kestenbaum bei Dewey verfolgt. Ein reiches Feld an Aussagen in den frühen Texten Deweys ist schlicht Ausdruck seines frommen puritanischen Glaubens, der durchaus nachwirkte, auch wenn Dewey sich später von ihm löste. Doch das Potenzial der frühen Texte Deweys nutzt Kestenbaum nur randständig. Noch in dem berühmten pädagogischen Glaubensbekenntnis, „My Pedagogic Creed“ (Dewey, 1897) ist von „Gott“ die Rede. Der Einfluss der Schriften des evangelikalen Theologen Elisha Mulford (†1885) auf den jungen Dewey hätte Erwähnung verdient (vgl. Retter, 2017, in progress).

Kestenbaum verfolgt einen anderen Ansatz. Man kann ihn festmachen an einer ethischen Grundforderung Deweys in den "Outlines of a Critical Theory of Ethics“ von 1891, die Kestenbaum in sein Buch übernahm: Wir sind gehalten, das tatsächlich erfahrene Gute einem möglichen Ideal des Guten zu überantworten. Dewey wörtlich: "to surrender the actual experienced good for a possible ideal good" (Dewey, 1891, S. 372). Dewey nannte aus der Poetik Beispiele, welche die Kunst als eine einzige große Erfah- 
rung verstehen lassen durch ihren Bezug zur transzendenten Sphäre. Ästhetische Erfahrung sei „Erfahrung in ihrer Unversehrtheit“: „Der Philosoph muss also die ästhetische Erfahrung aufsuchen, wenn er verstehen will, was Erfahrung ist" (Dewey, 2016, S. 321).

Ein umwerfender Satz! Man fragt sich: Warum empfahl Dewey nicht das Naturerleben als Erfahrung des Guten? Warum nicht die religiöse Erfahrung? Wurde doch letztere von Dewey ganz in der Nähe ästhetischer Erfahrung angesiedelt. Kestenbaum, der diese Aussage Deweys nicht erwähnt, kann sie dennoch erklären: Weil alle konkret wahrgenommene Kunst, indem sie Empfindungen weckt und Deutungen herausfordert, über sich selbst hinausweist. Kestenbaum nutzt vor allem Ästhetik, Ethik und Wertphilosophie Deweys, um bei ihm transzendente Bezüge deutlich zu machen. Das ist schon eindrucksvoll, wie Kestenbaum diese Fülle an Hinweisen erschließt. Zitate der Philosophen Nicholas Rescher und John N. Findley bilden dabei den Kontext.

Wenn man zu seinem gelungenen Beitrag noch einen Wunsch äußern darf, dann nur, um die Diskussion aufrecht zu erhalten. Wie Kestenbaum verdeutlicht, räumte Dewey jeder direkten positiven Erfahrung die Chance ein, in eine Sphäre des Ideellen zu transzendieren um fortzuleben. Es ist angemessen, Dewey Inspiration und Spiritualität zu attestieren. Doch sein Sinn für Transzendenz ist insofern begrenzt, als er den Begriff rein diesseitig, innerweltlich versteht. Die Vorstellung, dass etwas jenseits von Erfahrung existiert, hatte er beseitigt. Erfahrung ist in Deweys Philosophie alles, sie hat kein Jenseits. Selbst das Ideelle gehört zum Diesseits. „Experience“ kann sich auch hin zu einer Vorstellungswelt des Unsichtbaren („Unseen“) bewegen, die die Zukunft sowie Werte und Ideale betrifft. Dewey machte deutlich: Erfahrung hat natürliche Grenzen.

Im gehobenen Alltagsverständnis schwingen im Begriff Transzendenz Gott, die Himmelsmacht, das Numinose, das Heilige und ähnliche Bezeichnungen mit. Doch gerade dies gilt nach 1900 nicht mehr für Dewey, und dies zu wissen ist für die Leserschaft wichtig. Dewey nahm „Transzendenz“ nicht als Schlüsselbegriff seiner Wert- und Religionstheorie in Anspruch. Bei Dewey bildet vielmehr die kollektive Erinnerung der Geschichte eine solche Sphäre des Ideellen (vgl. Dewey, 2004, S. 291f.). In ihr sollen die moralischen, kulturellen, wissenschaftlichen Werte wie andererseits auch die Leiden und Opfer der Menschheit erhalten bleiben. Sie werden im kollektiven Gedächtnis jeder Generation gespeichert und weiter an die nächste Generation vermittelt. Vom Leiden sozialer Gruppen sagt Dewey - leider - nichts. Dieser innerweltlich-horizontale Transzendierungsprozess in der Weitergabe des Guten wäre mit dem vertikal gedachten Transzendenzbegriff nur unzureichend erfasst. Beides existiert bei Dewey nebeneinander. In bestimmten Situationen bedeutete Deweys Empfehlung, Mittel-Zweck-Strategien zu entwickeln, das pragmatische Verhindern jener Erfahrung, die sich in der Blütezeit seines Instrumentalismus die gesellschaftlich Geächteten wünschten: Nichtweiße hofften, die Erfahrung zu machen, willkommen zu sein und als normale Amerikaner zu gelten und nicht als „Neger“ separiert zu werden. Höhere Bildung wurde ihnen noch in den dreißiger Jahren verweigert. Von dem größten Philosophen Amerikas in der Krisenzeit in aller Öffentlichkeit ein herzliches Willkommen zu vernehmen, war ihnen nicht vergönnt.

Von "Gnade" (als Gewährung und Erfüllung menschlichen Sehnens) sprach Dewey nur selten, aber dann ebenfalls ganz innerweltlich, wenn es um eine Situation erfahrenen Glücks geht - den Moment tiefen wechselseitigen Verstehens, erfahrener Güte, Dankbarkeit, Wertschätzung, Liebe. 
Einen Augenblick gelungener Existenz bewusst zu erleben ist ein Geschenk. Es erhöht uns, weist über uns hinaus auf eine zeitenthobene, jenseitige Dimension. Nach James liegt der Kern des religiösen Glaubens in der Überzeugung, dass die sichtbare Welt umfasst wird von einer höheren unsichtbaren Welt, „the unseen order“. Mit ihr in Harmonie und Einklang leben zu wollen ist das Ziel religiösen Strebens. Diese unsichtbare Welt ist bei James real, sie untersteht - entsprechend dem Befund in James' Studien zur religiöse Erfahrung - der Annahme, Fürsichsein zu besitzen. Auch Dewey kannte eine Sphäre des Ideellen, Unsichtbaren. Doch eine von menschlicher Erfahrung unabhängige Existenz des Transzendenten, die das Schicksal des Menschen bestimmt, bestritt er, wie erwähnt, ausdrücklich. Ein Schlüsseltext für den Wandel der religiösen Anschauungen Deweys im Vergleich zur Zeit vor 1894 bildet der Essay: "Experience and Objective Idealism" von 1906. Hier sagte er am Ende:"An empiricism that acknowledges the transitive character of experience, and that acknowledges the possible control of the character of the transition by means of intelligent effort, has abundant opportunity to celebrate in productive art, genial morals, and impartial inquiry the grace and the severity of the ideal" (Dewey, 1906, S. 144).

Das Zitat bildet auch den Schlüssel zum Verständnis des Anliegens von Kestenbaum, der allerdings über die von Dewey geforderte Kontrolle der Wandlung ("transition“) konkreter Erfahrung ins Ideelle mittels „intelligent effort“ keine Aussage macht. Dewey erläuterte nicht, was genau „control of the character of transition" sein soll. Offenbar vermochte er die prinzipielle Forderung konkret gar nicht einzulösen.

Theologisch eröffnet der Beitrag von Kestenbaum die Möglichkeit, auf Rudolf Otto, tiefenpsychologisch auf Carl Gustav Jung zu verweisen. Dabei ist der Vergleich interessanter als die nur partiell gegebene Übereinstimmung. Kestenbaums Anliegen, bei Dewey sich nur auf die guten Qualitäten von Erfahrung zu stützen, um ihren ideellen Gehalt herauszuarbeiten, wurde ihm dadurch erleichtert, dass Dewey inhumanen, schlechten Erfahrungen wie Ausgebeutetwerden, Demütigung, Bedrohtsein allenfalls als böses Gegenbild des gewollten Guten Beachtung schenkte, doch nie (oder viel zu wenig) in die Abgründe realgesellschaftlicher Zustände wirklich eintauchte. Das wird bei Kestenbaum kaum zur Sprache gebracht.

Kestenbaum macht indirekt deutlich: Dewey besaß in seinem Idealismus keinen transzendenten Ort der kollektiven Erfahrung des Bösen von unterdrückten Gruppen, um dieses emotional verankerte Wissen in Generationen übergreifender historischer Erinnerung wach zu halten. Doch das Wachhalten von „Erinnerung" hat die amerikanische (wie auch die deutsche) Geschichte durchaus nötig in Bezug auf benachteiligte Minoritäten, Klassen und Rassen. In der Möglichkeit, dem personalen Gottesverständnis wie der Verzweiflung und der Hoffnung in der Musik Ausdruck zu geben, besaß Black Culture ein kostbares Gefäß kollektiv erinnerter und ständig aktivierter Erfahrung. Obwohl Dewey Interesse besaß an der Harlem-Renaissance New Yorks in den zwanziger Jahren - der ersten auch international bedeutsamen Anerkennung afroamerikanischer Kultur in Musik, Poetik, Literatur, Kunsthandwerk -, schweigt sein Werk dazu. Deweys Buch „Kunst als Erfahrung“ belegt, dass er kein musikalisches Interesse besaß. Angesichts der Bedeutung der Musik für die (christliche) Religion fragt man sich, ob andere Pragmatisten einem Händel-Oratorium, einer Bachschen Passion oder einer Haydn-Messe etwas abgewinnen konnten. In den USA vor hundert Jahren völlig undenkbar? Ja, vielleicht, aber die Experten schweigen zu diesem Thema.

Die tiefgehende Kritik des Theologen Reinhold Niebuhr Anfang der dreißiger Jahre (vgl. Retter, in Hohr \& Retter, 2009, S. 126f.), Deweys idealistische Sozialtheorie gehe an dem herrschenden Elend in der 
amerikanischen Gesellschaft völlig vorbei, ist bekannt. Ebenso kritisiert Niebuhr Deweys Religionstheorie. Es war die Zeit der großen Depression, in der verzweifelte Menschen nur noch im Gebet Trost fanden. Dewey hingegen schaffte Gott ab, um an dessen Stelle die Ideale der Menschheit auszubreiten.

Niebuhrs Dewey-Kritik, die Kestenbaum unerwähnt lässt, wurde von anderen Autoren als berechtigt angesehen (Rice, 1993; Zakai, 2008, Rummenie, 2010). Aus der Kritik kann man den Schluss ziehen: Bei Dewey existierte letztlich keine große Übergangsschwelle von der Wirklichkeitserfahrung zur ideellen Sphäre. Dewey wechselte lediglich vom unverdaulich gewordenen „absoluten“ Idealismus in die leichter bekömmliche Form eines selbstgeschaffenen Idealismus. Mit ihm bekämpfte er, an der „Social Frontier" ganz vorn stehend, die Unbilden der Zeit. Er hatte als Vertreter des liberalen Progressivismus immer eine bessere Zukunft vor Augen, die nur deshalb noch nicht da sei, weil ihre Bedingungen, wie er sagte, erst noch geschaffen werden müssen. Das klingt nach einem infiniten Regress.

Matthias Jung geht in unserem Rezensionsband der Frage nach, ob nicht bei Dewey ein Spannungsverhältnis bestehe zwischen seinem Begriff von qualitativer, unmittelbarer Erfahrung („qualitative experience“), und seiner naturalistischen Auffassung von Religion („naturalized religion“). Die Frage bejahend argumentiert Jung so vorsichtig wie umsichtig. Jung will Dewey nicht widerlegen, allenfalls dessen Argumentation kritisch zur Diskussion stellen. Dewey meinte offenbar, den Theismus widerlegen zu können, indem er unterschied zwischen „Erfahrung“ und der Interpretation dieser Erfahrung. Als ob nicht jede Erfahrung an unmittelbare Deutung gebunden ist! Dewey argumentierte: Wenn Gläubige ihre persönliche Erfahrung als Beleg für Gottes Existenz anführen, handele sich um „Interpretation“ von Erfahrung. Dewey sah offenbar nicht, dass jede innere Regung nur durch Interpretation in Form eines sprachlichen Urteils - emotional, kognitiv, sprachlich - ihren Geltungsanspruch als Erfahrung gewinnt. Jung hat völlig recht. Man kann ihm dankbar sein, dass er seinen Beitrag auf dieses eine Argument der Kritik beschränkt, es dafür aber sorgsam ausbreitet.

\section{John Dewey und Hilary Putnam}

Im Mittelpunkt des Beitrages von Magnus Schlette steht Hilary Putnam (†2016). Deweys Religionsschrift, „A Common Faith“ (deutsch: Dewey, 2004) wird hier gleichsam zum Tool für die Überprüfung der Religiosität eines bekannten Philosophen. Putnams frühe akademische Lehrer Hans Reichenbach und Rudolf Carnap (beide emigrierten aus Hitlerdeutschland) gehörten zu jener Generation von Philosophen, die den Deweyanismus als die führende Philosophie in den USA ablösten durch den logischen Empirismus und die analytische Philosophie. Putnams wissenschaftliche Leistungen gehen über Beiträge zu Mathematik, formaler Logik sowie Erkenntnis- und Wissenschaftstheorie hinaus. Sie erstrecken sich auch auf politische und gesellschaftsrelevante Fragen. Seine philosophischen Standpunkte veränderten sich im Lauf der Zeit. Eine Rolle spielen dabei Grundsätze des Pragmatismus, ebenso die Anschauungen bedeutender jüdischer Philosophen wie Martin Buber, Emmanuel Levinas, Franz Rosenzweig. Wichtig wurde nicht zuletzt Ludwig Wittgenstein. Schlette zeigt einfühlsam, wie Putnam mit zunehmender Hinwendung zum gläubigen, praktizierenden Judentum die religiöse Frage in einem Prozess der Selbstklärung zu beantworten suchte. Die intellektuelle Auseinandersetzung mit Deweys „A Common Faith“ fand darin ihren Abschluss, dass Putnam Deweys Streichung des Gottesglaubens zurückwies. Das, was Dewey religiöser Erfahrung an Wert zuzubilligen bereit war, empfand Putnam als Reduktionismus. Wie Dewey schloss Putnam ein Fortleben nach dem Tod aus. Hierzu sei angemerkt, 
dass die „postmortale Endlagerung“ (P. Sloterdijk) auch im heutigen Protestantismus vielfach nicht mehr entscheidend ist für das Festhalten am evangelischen Glauben.

Schlette zeigt ferner, wie Wittgensteins Betonung der Bildhaftigkeit der Sprache ein befreiendes Moment für den Glauben darstellt. Nur über seine Kontexte ist religiöser Glaube interpretierbar. Martin Bubers Philosophie des „Ich und Du“ bot schließlich Putnam die Chance, eine Versöhnung zwischen der religiösen und der wissenschaftlich-philosophischen Antwort auf die Gottesfrage zu erreichen. Schlettes Beitrag enthüllt, in welchem Ausmaß religiös-weltanschauliche Überzeugungen selbst bei einem so bedeutenden Wissenschaftler wie Putnam als vorlaufende subjektive Kontexte eingehen in Aussagen, die von der Scientific Community als „wissenschaftlich gerechtfertigt" bewertet werden und objektive Anerkennung finden.

Im Beitrag von Wayne Proudfoot über „Pragmatism, Naturalism, and Genealogy“ geht es um einen für die pragmatische Forschungslogik zentralen Aspekt: Besonders Dewey verfolgte die These, dass ethische Maßstäbe, Werte und Religion, die der Idealismus als absolute, naturgegebene und deshalb unantastbare Größen in sein Wirklichkeitsverständnis einbringt, aus lebenspraktischen wie machtpolitischen Zusammenhängen historischer Epochen stammen. Im historischen Prozess wurden sie umgeformt zu unhinterfragbaren Wahrheiten, die Herrschaftsinteressen dienen. Deshalb sei ihnen, so Dewey, jeder zeitenthobene Absolutheitsanspruch abzusprechen.

Proudfoot verweist in diesem Kontext auf Nietzsches Schrift „Zur Genealogie der Moral“, die, polemisch sehr viel schärfer gefasst, zur Bestätigung der These Deweys dienen kann. Dazu sei angemerkt: Die Auflösung von Absolutheitsansprüchen in den Geisteswissenschaften zugunsten des historischen Nachweises ihres zeitgebundenen Ursprunges war keineswegs nur ein Anliegen des amerikanischen Pragmatismus, sondern um 1900 in Europa, vor allem im deutschsprachigen Raum, mit der Durchsetzung der historisch-kritischen Methode in den Geisteswissenschaften auch Bestandteil (vornehmlich protestantischer) Universitätstheologie geworden.

Im Rezensionsband verweist Proudfoot auf Deweys und James' These, der tradierte Idealismus sei immer dem Zirkelschluss erlegen, dass das, was als objektiv wahr bewiesen werden soll, bereits in den vorlaufenden Voraussetzungen enthalten sei. Diese Kritik ist einsichtig, doch auf den Pragmatismus trifft sie weit mehr zu. Mit dem von Proudfoot untersuchten Konzept „inquiry“ - Schlüsselbegriff in Deweys Logik - suchte Dewey zu vermeiden, sich einem derartigen Zirkelschluss auszusetzen. Der historische Abstand zeigt, dass die Forschungslogik Deweys, die - wie Proudfoot herausarbeitete - auch Unklarheiten im Pragmatismus von James überwinden wollte, der guten Absicht nicht gerecht wird. Ein Forschungskonzept, das Forscher und Forschungsobjekt, - Aktion/Reaktion bzw. Organismus/Umwelt nicht trennt, sondern als Erfahrungsganzheit sehen möchte, wie dies in Deweys Logik der Fall war (seit seinem berühmten Aufsatz über den Reflexbogen von 1896), bringt anfangs immer schon das ein, was am Ende herauskommen soll. Die „Handlungsforschung“ der 68er, die eine Parallele zu Deweys Inquiry bildete, attackierte die um Objektivität bemühten Methoden der empirischen Forschung. Doch die emanzipative Selbstaufklärung durch das Handeln von Subjekten, die nicht mehr Objekte (Probanden) eines experimentellen Versuchsplans sein wollten, blieb in der Hoch-Zeit der 68er immer auch ein Stück sich selbst erfüllender Prophezeiung und ist heute nur noch historisch erwähnenswert.

Auch wenn Dewey zu Recht jede „Naturalisierung“ der Geschichte durch Ideologie und Glauben zurückwies, war er alles andere als ein kritisch arbeitender Historiker. Es gibt zwar einige gute wissen- 
schaftshistorische Aufsätze von ihm, wie etwa über Thomas Hobbes. Dewey war aber als Darwinist um 1900 viel zu sehr vom Progressivismus seiner Zeit beflügelt, als dass er vermocht hätte, die Geschichte Amerikas anders als evolutionär, hoch selektiv und idealistisch verklärt zu betrachten. Es war ethnozentrisches Denken, das Dewey, dem Geist der Zeit folgend, dazu brachte, den „Wilden“ als guten Menschen, aber evolutionär unten, die Herrschaftsinteressen rechtfertigende amerikanische Kultur jedoch ganz oben zu sehen. Die teleologische Sicht gesellschaftlichen Wachstums (growth) in seinem organischen Denken war Bestandteil seines Progressivismus.

Der Erfahrungsgewinn, den man Proudfoots Text entnehmen kann, liegt in der schärferen Konturierung des Basis-Dilemmas einer vom Pragmatismus beeinflussten Sozialforschung: Je voraussetzungsloser Religions- und Sozialwissenschaftler forschen wollen, desto stärker bewegen sie sich in Aussagenbereichen, die inhaltlich wenig Relevanz aufweisen. Dies zeigt nicht nur das Schicksal des Behaviorismus, sondern in anderer Weise auch Deweys Religionsschrift. Nach Deweys Vorstellung in „A Common Faith“ liegt substanzielle religiöse Erfahrung allen anderen Erfahrungen als allgemeine Basis zu Grunde. In der Konsequenz solchen Verständnisses ist Erfahrung weitgehend inhaltsleer. Den Titel seiner Religionsschrift dürfte Dewey mit Bedacht gewählt haben - auch als Spitze gegen seinen größten Gegner, die katholische Kirche: Der katholische Glaube, altgriechisch „pistis katholikos“, ist der allgemeine Glaube. Dass Deweys Text dem keineswegs nahe kommt, sondern eher die ironische Bezeichnung „uncommon faith“ verdient, deuteten einige Kritiker an. In Deweys Predigttext über „Christianity and Democracy“ von 1892 sah das noch ganz anders aus. Hier und in einigen weiteren Texten jener akademischen Frühzeit Deweys machte er die Demokratie zum Erfüllungsort des Reiches Gottes auf Erden. Wenig später in Chicago wurde die Metapher Bestandteil des Social Gospel. Dewey übertrug sie auf jene Vision von Demokratie, deren Basis die Settlement-Bewegung bildete - konzentriert auf die Erfahrung von Jane Addams „Hull House“. Nirgendwo anders war diese Erfahrung zu finden. Dass Dewey nachbarschaftliches, gutes Zusammenleben als Modell für die politische Steuerung der mächtigsten Nation der Welt diente, machte seinen Demokratiebegriff so eindrucksvoll. Anstatt diese Demokratievorstellung kritisch zu hinterfragen, wurde sie gefeiert. Man verdrängte, dass Dewey ein real nicht einlösbares Ideal-Konstrukt präsentierte, mit dem konkurrierende soziale Vielfalt, die Zerstörungen des Kapitalismus und politische Dilemmata nicht zu bewältigen waren. Vieles an Deweys reifem Demokratiekonhzept als Gemeinschaft sozialer Teilhabe ist im Geist von „brotherhood“ weltlich gewordener Dienst am Nächsten. Die Demokratie-Idee Deweys ist so spirituell durchwirkt, dass man sie als ein Stück säkularisierter Theologie bezeichnen kann. Sie bildete die weltliche Alternative zur „beloved community“ von Royce - mit dem Unterschied, dass Dewey fatalerweise beanspruchte, damit einen politisch ernst zu nehmenden Begriff von moderner Demokratie geliefert zu haben.

\section{Josiah Royce und William James}

Sollte man heute in der Lage sein, den amerikanischen Pragmatismus der Zeit um und nach 1900 mit Dewey, Mead, James und Peirce zu verbinden, so bleibt hierzulande der Name Josiah Royce doch völlig unbekannt, allenfalls findet man den Hinweis, dass Royce ein Gegner des Pragmatismus gewesen sei. Um diese Fehlinformation zu korrigieren, sei ein Blick auf jene beiden Texte des Rezensionsbandes geworfen, die William James und Josiah Royce gemeinsam betreffen. Sie stammen von Ludwig Nagl und Hans Joas. 
Von Haus aus ist Joas historisch interessierter Soziologe, dem nach seiner Promotion über George H. Mead das Verdienst zukommt, ab den neunziger Jahren eine neue Beachtung des amerikanischen Pragmatismus erreicht und dabei auch die Rolle John Deweys unterstrichen zu haben, um dann als Religionssoziologe hervorzutreten. Er darf heute der vielleicht einflussreichste deutsche Religionsphilosoph genannt werden. Im Rezensionsband reflektiert er Gemeinsamkeit und Differenz religiöser Erfahrung bei William James und Josiah Royce. Beide, James und Royce, lehrten vor und nach 1900 an der Harvard Universität in Cambridge.

Bei Joas spürt man die Absicht, die Leserschaft vor allem mit Josiah Royce als Schüler, Freund und Kollegen von William James bekannt zu machen. Der zweite Beitrag stammt von dem Wiener Philosophen Ludwig Nagl, seit langem ausgewiesen durch Forschungsarbeiten zum amerikanischen Pragmatismus einschließlich zu dessen Religionsphilosophie. Nagl ist heute im deutschsprachigen Raum vermutlich der beste Kenner der Royceschen Philosophie. Nun zu den Einzelheiten.

Nachdem Royce vor mehr als 100 Jahren starb, macht Joas' Beitrag zunächst das Fehlen einer RoyceRezeption in Deutschland sichtbar: Nur ein einziges Werk, die Kölner Dissertation von Karl-Theo Humbach (1964), vermag er zu nennen. Doch auch die 1926 veröffentliche, durch Bruno Bauch betreute (inhaltlich eher abschreckende) Jenaer Dissertation des aus den USA stammenden Walter Rothmann über „Josiah Royces Versuch einer Synthese von Pragmatismus und Objektivität“ ist erwähnenswert, denn nicht nur Royce, sondern auch der Pragmatismus erscheinen im Titel des Bändchens. In der Weimarer Republik war das eine Rarität. Joas bewertet Royces Buch von 1912, „The Sources of Religious Insight", das aus Gastvorlesungen hervorging, als kritische Auseinandersetzung mit James' "Varieties of Religious Experience“. In Royces zweibändigem Werk von 1914, „The Problem of Christianity“, das ebenfalls Gastvorlesungen wiedergibt, treten demgegenüber stärker Peirce und dessen Semiotik in den Vordergrund. Royces posthume Kritik an James fasst Joas in sieben Punkten zusammen. Es liegt nahe, dass Joas schließlich auch skizziert, mit welchen Gegenargumenten der verstorbene James seinem in bestimmten Punkten anders denkenden Kollegen vermutlich geantwortet hätte ? für die Leserschaft ist diese Reflexion eine willkommene Ergänzung.

Die größte Differenz zwischen Royce und James liegt nach Joas darin (und auch dies ist nachvollziehbar), dass Royce einen mehrfach von Krisen heimgesuchten, doch starken gemeinschaftsbestimmten Glauben an Gott besaß, der die Hoffnung auf Versöhnung der Menschern einschloss. James, der immer bereit war, den Willen zum Glauben und das Gute des Gottvertrauens zu verteidigen, ging der Bekenntnischarakter der Royceschen Philosophie viel zu weit. In der Tat: Jener Philosophie der Pflichttreue gegenüber Gott (Philosophy of Loyalty), die Royce als Basis des lebendigen Glaubens ansah, folgte James nicht. James' Eltern waren oft in Europa. Er selbst war es in seiner Jugend ebenfalls geprägt durch Internatsschulen, die er in Deutschland und der Schweiz besuchte, und Universitätsstudien, später auch durch Forschungsaufenthalte und immer wieder durch Kuraufenthalte. Von Deutschland abgesehen, hielt er sich auch in Frankreich und nicht zuletzt bei seinem Bruder Henry, dem berühmten Schriftsteller, in England auf. James war nicht nur gebildet, sondern er „hatte Bildung“. Als der Vater im Sterben lag, schrieb William an ihn einen bewegenden Abschiedsbrief an dessen Ende er sagte: Er wisse nicht, ob es ein Drüben gebe und ob man sich wiedersehe, aber sollte dies so sein, so wären alle Fragen gelöst und alles wäre gerechtfertigt. Einen frommen christlichen Gemeinschaftsglauben, wie ihn Royce besaß, hatte James nicht. 
Aus der Distanz von über hundert Jahren betrachtet ist der beschriebene Unterschied im Glauben zwischen James und Royce nicht unermesslich groß. Die Differenz in ihrer religiösen Überzeugung stand in engem Zusammenhang mit der Differenz ihrer Philosophie: Royce vertrat eine „christliche Metaphysik“ (Frank M. Oppenheim, S.J.), in welcher der Mensch Versöhnung erfährt in einer religiös gleichgesinnten Beloved Community der sichtbaren wie der unsichtbaren Kirche. Die unsichtbare Kirche Roycescher Auffasssung kann man sich als locker in augustinisch-calvinischer Tradition stehend vorstellen. Es ist, nebenbei bemerkt, wohl kein Zufall, dass das neue Interesse an der Philosophie des Protestanten Royce bei einzelnen katholischen Hochschullehrern in den USA wie in Deutschland ein reges Interesse begleitet.

Der besondere Wert des Beitrages von Ludwig Nagl über Royce besteht unter anderem darin, auf die Bezüge zum Katholizismus der Zeit aufmerksam zu machen. So verweist er auf das Interesse liberaler katholischer Kreise in Europa für den Pragmatismus. Der Katholizismus war in der Krise, nachdem die römische Kurie durch mehrere Lehrschreiben öffentlich machte, einen Abwehrkampf gegen die modernen Zeiterscheinungen zu führen, insbesondere gegen Demokratie und Liberalismus. Aufs Ganze gesehen gewann die Kirche diesen Kampf nicht, der viele Katholiken, die ein kirchliches Amt wahrnahmen, in Gewissensnot brachte.

Nagls Text macht der Leserschaft noch einmal einige Unterschiede der Sichtweisen zwischen Royce und James klar. Royces Pragmatismusverständnis war von der Nähe zu Kant und dem deutschen Idealismus geprägt. James bemühte sich um eine versöhnende Position, indem er den Pragmatismus als neue Botschaft mit europäischen Wurzeln verkündete. Radikal ablehnend standen sich nach 1900 nur Royce und Dewey gegenüber. In Royces Betonung des Community-Gedankens sieht Nagl eine Kritik an negativen Erscheinungen der modernen Zeit, die Royce von Zeitgenossen als allzu darwinistischindividualistisch interpretiert sah; Royce forderte eine philosophische Neuinterpretation der Lehre Darwins als Kosmologie. James' Denken sah Royce zu stark geprägt durch die erste Sturm- und Drangperiode des Darwinismus in Amerika (die allerdings bei Dewey wesentlich stärker auftrat). Royces „beloved community“ besaß die Funktion eines Schutzschildes gegen den grassierenden Sozialdarwinismus. Die im postdarwinschen Zeitalter florierenden Theorien über die Gefährdung der Volkssubstanz und die These vom „Survival of the Fittest“ (Herbert Spencer) leistete, verstärkt durch die Massenimmigration, nationalen Ängsten Vorschub, so dass US-Bundesstaaten in pragmatischer Absicht Sterilisationsgesetze beschlossen, beginnend mit Indiana, 1907. Die Maßnahmen trafen: Geistes-, Sexual-, Alkoholkranke, „feeble minded“, als entwicklungsunfähg betrachtete Gefängnis- und Anstaltsinsassen, Schwerkriminelle, „black people“, soweit deren Bildungsfähigkeit völlig aussichtslos zu sein schien. Ein Protest der amerikanischen Pragmatisten gegen diesen Angriff auf die Menschenwürde ist nicht überliefert, doch die Begeisterung F.C.S. Schillers für die „Eugenik“ ist nachlesbar (Schiller, 1932).

Der Beitrag von Vincent Colapietro im Rezensionsband lässt noch einmal den Blick von Royce zu Peirce schweifen. Dabei macht er die Tiefe der religiösen Dimension im Denken von Peirce besonders deutlich. Colapietro stellt fest, dass sich die Standpunkte von Peirce und Royce in großen Teilen überlappten (Colapietro, in Deuser et al., 2016, S. 189). Der christliche Gottesglaube, eine christliche Metaphysik, die in der dreistelligen Zeichenlehre Peirces die göttliche Trinität in Erscheinung treten lässt (wie Deuser 2004 gezeigt hatte) und nicht zuletzt die soziale Bestimmung des Menschen bildeten zentrale Momente im Denken von Peirce und Royce, die sie viel näher aneinander rücken lassen, als dies in bisherigen Deutungen des Pragmatismus beachtet wurde. 
Die Gegenüberstellung der Religionsphilosophie von Royce und James wird erwartungsgemäß den stärker sozial bestimmten Standpunkt von Royce und die mehr individuumzentrierte Position von James erwähnen, was sich in den Beiträgen von Joas und Nagl nur andeutet. Nicht vergessen werden sollte, dass Royce die individuumbezogene Position durchaus reflektierte (zum Beispiel in seiner an Kant orientierten Moralphilosophie), während es ein besonderes Anliegen von Michel Slater (2014, S. 23) ist, die soziale Seite in der Religionspsychologie James' deutlich zu machen, um sie vor Unterschätzung zu bewahren.

William James entwickelte nicht nur die Vorstellung von der Pluralität des Universums, sondern auch vom endlichen, finiten Gott. Christian Polke weist im Rezensionsband darauf hin, dass viele Intellektuelle am Ende des 19. Jahrhunderts sich vom allmächtigen, ewigen Gott verabschiedeten; darunter auch der Bostoner Theologe Edgar Brightman, dessen Standpunkt Polke mit dem von James vergleicht. Polke setzt dem finiten Gott argumentativ „expressiven Theismus“ entgegen. Was er beschreibt, wird bei einzelnen Menschen offenbar, wenn sie von einem existenziellen Erlebnis berichten, das sie zu Gott und zum Glauben (zurück-) gebracht hat. Sie beginnen, ihrem Leben einen neuen Sinn zu geben - etwa nach Errettung aus Lebensgefahr oder erlebter Dankbarkeit im Falle geleisteter Hilfe für Menschen in Not.

James' funktionaler Gottesbegriff verblieb im Endlichen und war nicht absolut oder unendlich gedacht. Ein unvollständiger Gott ist schon eine merkwürdige Konstruktion, die, von der Kanzel im Gottesdienst verkündet, dem Geistlichen vermutlich ein Lehrzuchtverfahren oder Schlimmeres bescheren würde. Auch Polke akzeptiert ein solches Gottesverständnis nicht. Für den gläubigen Christen ist James' Gedanke in der Tat kaum befriedigend. Eine im Glauben veränderte Sicht Gottes, welche Allmacht nicht mehr zum Prädikat des Gottesbegriffs rechnet, vollzog Hans Jonas als Überlebender seiner in Auschwitz ermordeten Familienangehörigen. Man kennt Jonas' unvergessene Rede von 1984 über den „Gottesbegriff nach Auschwitz". Er greift zurück auf die Frage Hiobs: Herr, wo warst du? Auschwitz veränderte das Bild von Gott bei denjenigen, die, was auch immer geschieht, von Gott nicht lassen können: Gott kann nicht (mehr) als Allmächtiger für den Genozid an seinem Volk und zugleich für das versprochene Heil, für Erbarmen und Liebe in Anspruch genommen werden. Hält man sich an Letzteres, steht allein Gottes Barmherzigkeit im Zentrum. Ob man diese Interpretation mit der totalen Selbstentäußerung des Schöpfers im Schöpfungsakt begründet, für den Gott alles gegeben habe (entsprechend Jonas' Darstellung), oder ob man diese Begrenzung Gottes unerklärt lässt, ist hier unerheblich. Wichtiger ist: Nicht die analytische, außerhalb des Glaubens stehende Sicht des finiten Gottes von James, sondern die tragische, im Glauben vollzogene Wendung von Jonas - auf Gott hin - zeigt Authentizität.

Polke erwähnt Hans Jonas' Beitrag zu diesem Problemkreis nicht. Mir scheint er wichtig genug, um die Intention Polkes zu stärken. Sein Beitrag macht einmal mehr deutlich, dass die rationale Erklärung Gottes als einer reinen Wunschprojektion (Ludwig Feuerbach) von der existenziellen Gotteserfahrung, die Glauben und Lebensführung bestimmt, überhaupt nicht tangiert wird. Deweyaner können, anders als Dewey es vermochte, von tiefem oder weniger tiefem Glauben erfüllt sein. In diesem Sinn argumentiert auch Slater, der betont, Deweys radikaler Antitheismus beinhalte kein Argument, das auch nur ansatzweise in der Lage sei, jemanden davon zu überzeugen, dem tradierten Glauben den Rücken zu kehren (Slater, 2014, S. 130). Ebenso wenig bilde Deweys Sicht der Religion eine normative Vorgabe für das moderne Verständnis von Pragmatismus.

Deweys Meinung zur Religion erscheint im hohen Alter erstaunlich eng, ja antiliberal. Pragmatisches Denken ist viabel. Es öffnet und beschreitet viele Wege. Gerade dort, wo unter den Vertretern des klas- 
sischen Pragmatismus beachtliche Differenzen der Sichtweisen auftraten wie im Fall der Religion, bedeutet das Bekenntnis zum Pragmatismus heute, religiöse Vielfalt nicht nur zu dulden, sondern sich in dieser Vielfalt wohl zu fühlen (Slater, 2014, S. 182). Das entspricht dem Standpunkt von William James.

Wilhelm Wundt prägte den Satz: „Man kann den Pragmatismus nicht verstehen, wenn man nicht vor allem seine Religionsphilosophie in Betracht zieht" (Wundt, 21921, S. 97). Die Aussage fiel drei Jahre vor Beginn des Ersten Weltkrieg und war Zunder für das lodernde Feuer der Auseinandersetzungen um die neue American Philosophy in Europa. Liest man die jüngsten Beiträge von Religionsphilosophen zum Pragmatismus, wie sie hier ausgebreitet wurden, wird klar, dass Wundts Statement erst heute seine tiefere Wahrheit enthüllt. Was können Erziehungswissenschaftler daraus lernen? Ein bekanntes Nietzsche-Wort abwandelnd möchte man ihnen zurufen: „Du gehst zum Pragmatismus? Vergiss jene Theologen und Religionsphilosophen nicht, die ihn besser kennen, als Universitätspädagogen ahnen!“

\section{Ausblick}

James' und Deweys Äußerungen über die letzte Dinge sind aufs Ganze gesehen zurückhaltend, weisen jedoch wesentliche Unterschiede auf. Sie machen deutlich, in welchen Abstufungen die Verblassung des Gottesglaubens im ersten Jahrzehnt des 20. Jahrhunderts (und später) in Erscheinung trat. Schon vor 1900 waren in Europa die Nachwirkungen der Ideen von Ludwig Feuerbach, Karl Marx, Friedrich Nietzsche und Charles Darwin in Intellektuellen-, Künstler- und Literatenkreisen ebenso wie in der Arbeiterschaft dergestalt wirksam, dass Kirche und Christentum rasant an Einfluss verloren. Universitätstheologie und kirchliche Kreise waren sich nicht mehr sicher, wie sie mit der Abwendung von der tradierten Religion in vielen gesellschaftlichen Gruppen umgehen sollten. Verweise auf das Strafgericht Gottes wirkten schon lange nicht mehr. Durch wachsende Widersprüche zwischen den Ergebnissen historisch-kritischer Forschung und der Lehre Darwins einerseits, kirchlicher Lehre andererseits wuchsen die Spannungen innerhalb der akademischen Theologie.

Es wäre unsinnig, im deutschen Kaiserreich heute nur engen Nationalismus feststellen zu wollen, ohne nicht auch die Bereitschaft zu liberaler Kooperation und moderner Vielfalt zu sehen. In der deutschen Theologie standen zum Beispiel Adolf von Harnack, Ernst Troeltsch und Otto Baumgarten für diese offene Haltung. Zuständig für die Bearbeitung der neu aufbrechenden Frage, „Was ist der Mensch - was gibt dem Leben Sinn?" wurde unter anderem die sich neu formierende Religionsphilosophie. Im akademischen Raum besaß die Theologie zwar Reputation, aber für die Verarbeitung des neuen Wissens über den Menschen in einer Epoche der Wissensexplosion gewannen an ihrer Stelle Anthropologie und Religionsphilosophie, später auch die Religionssoziologie an Boden - durch Deutungsmuster, die quer zu theologischer Dogmatik stehen. Erst der historische Rückblick macht sichtbar, dass der Pragmatismus um 1900 eine wissenschaftstheoretische Kompensationsfunktion wahrnahm. Das lernt man aus dem hier vorgestellten Tagungsband, auch ohne dass seine Autoren dies ansprechen.

Erinnert sei an jene vielzitierte Denkfigur, die Odo Marquard in kompensatorischer Absicht zur Kennzeichnung der Lage der Philosophie benutzte. Vom Pragmatismus sprach Marquard nicht. Doch wenn man Marquards Reclam-Bändchen „Abschied vom Prinzipiellen“ gelesen hat, wird einem heute klar: Der amerikanische Pragmatismus mit seinem religiösen Hintergrund war ein Kompensationsprodukt im Prozess der geistigen Verselbständigung der USA. Amerika wollte eine eigenständige Philosophie kreieren, abgelöst von Europa; dabei waren in den vorangegangenen Epochen die Repräsentanten die- 
ser Philosophie bis weit über die erste Hälfte des 19. Jahrhunderts hinaus Theologen, und die Philosophie war europäisch.

Die Pragmatisten Amerikas änderten dies. Sie machten vieles einfacher, manches allzu einfach. Dabei spielte die Religion eine - im Einzelnen unterschiedliche - Rolle bei der Bearbeitung eines Basisproblems: James und noch stärker Dewey wollten das Absolute im System idealistischer Philosophien verabschieden, besaßen aber keine tragfähiges Fundierung für die eigene Philosophie, so dass man das, was man glaubte abgeschafft zu haben, in anderer Form ungewollt wieder einführte: Idealismus und Metaphysik.

Zur logischen Verankerung von Experience, Erfahrung, als Basiskonzept des Pragmatismus war man genötigt, auf ein psychologisches Konzept zurückzugreifen, das im Raum stand, ohne dass sein Urheber Franz Brentano in den USA eine Rolle spielte. Es ging um die These, dass eine psychische Vorstellung auf einer Intention bzw. auf einem Akt mit Verweisungscharakter beruht. Psychologische Konstrukte in vollwertige Philosophie überzuführen war für die Vertreter des Pragmatismus nicht einfach. Dewey hat lebenslang daran gearbeitet. Die religiöse Schiene bot sich an zur Kompensation dieses Defizits: Peirce und Royce nutzten sie, James fand im „Willen zu glauben“ einen eleganten funktionalen Mittelweg zwischen Glaubensergriffenheit und Glaubensdistanz, während der späte Dewey die Absetzung Gottes unter Rückholung des Glaubens ins Diesseits vollzog. Damit wird die Vielfalt von Standpunkten im Pragmatismus deutlich. Sie ist die Antwort auf eine schlichte Frage, „Wie hältst du's mit der Religion?“ (die "Gretchenfrage“ in Goethes Drama Faust), die klar zu beantworten schon Goethe ziemlich schwer fiel.

Der Prozess der Ablösung der Theologie als Deutungsinstanz für das soziale Leben ging in Europa schneller als in den USA vonstatten. Doch auch in den USA begann die Theologie ihre Zuständigkeit zu verlieren, die sie früher für alle Lebensgebiete in Anspruch genommen hatte. An ihre Stelle traten religiöse Bewegungen, die in Spannung zu den etablierten Kirchen standen. Theologischer Funktionsverlust (Inkompetenz) erzeugte Kompensationsbedarf. Neue Kompetenz war gefragt. Anthropologie, Religionsphilosophie und Religionssoziologie entstanden, um es mit der ironischen Eloquenz eines für sprachliche Kreativität bekannten Philosophen zu sagen, im Zuge der vom Zeitgeist geforderten „Inkompetenzkompensationskompetenz" (Marquard, 1987, S. 23ff.).

Mit dem Pragmatismus James', Deweys und Meads wurde die Welt diesseitige Erfahrungswelt, doch damit wurde sie für den Menschen keineswegs sicherer - trotz Hoffnung auf innerweltliches Glück. Auf Glück zu hoffen, um langes Leid ertragen zu können, ist nach der Gebrochenheit der historischen Erfahrung des 20. Jahrhundert kaum denkbar, ohne dass dabei der Religion eine wichtige Rolle zukommt. Die Religion wird gebraucht, denn nur sie vermag die absoluten Werte des Humanum, der Menschenrechte, der Würde der Person zu binden. Wie aber die Religion in Anspruch nehmen, wenn Theologie und Kirche nicht mehr für das gesellschaftliche Ganze stehen?

Möglichkeiten dazu eröffnet das Konzept der Selbsttranzendenz. Mit Selbsttranszendenz wollte Viktor Frankl (2005, S. 335) ein Zeichen setzen gegen Anthropomorphismus, Werte-Relativismus, Atheismus. Frankl (†1997) war Überlebender des Holocaust, seine Familienangehörigen wurden in Auschwitz ermordet. Mit dieser Erfahrung begründete er, tief gläubig, die Existenzanalyse und Logotherapie. Wie oben erwähnt, sah Putnam Deweys Religionsauffassung als reduktionistisch an und lehnte sie ab. Frankl hatte denselben Einwand des Reduktionismus gegenüber der Psychoanalyse Freuds, die die 
Gottesidee zur Projektion der Vaterimago erklärte. Frankl sprach von Selbsttranszendenz als einem anthropologischen Merkmal, das die personale Gotteserfahrung ermöglicht. Existenzanalyse und Logotherapie gehen vom werterfüllten, sinnsuchenden Menschen aus. Max Schelers Anthropologie und dessen Begriff der Welthabe besaßen für Frankl zentrale Bedeutung. Schelers letzte Schrift, „Die Stellung des Menschen im Kosmos", ist der klassische anthropologische Text europäischer Philosophie. Ihm gegenüber bildet Deweys Sicht des Grundverhältnisses von Mensch und Welt den Gegenpol. Als das einzige Wesen, das über geistige Freiheit verfügt, vermag nach Scheler nur der Mensch „nein!“ zu sagen. Deweys Ethik macht allein Erfahrung zum Maßstab des Handelns: Im Licht Darwins ist der Mensch Organismus, der Anpassung (adjustment) betreibt und dabei in wechselseitiger Interaktion mit der Umwelt steht. Frankl sagte demgegenüber: „Menschsein weist immer schon über sich selbst hinaus, und die Transzendenz ihrer selbst ist die Essenz menschlicher Existenz" (Frankl, 2005, S. 9).

Es ist wohl kein Zufall, dass die Frage von Hans Joas: „Braucht der Mensch Religion?“ die er auf dem Ökumenischen Kirchentag 2003 stellte und sie mit seinem Konzept der Selbsttranszendenz positiv beantwortete, in der Öffentlichkeit ein größeres Echo fand als Frankl Jahrzehnte zuvor. Zunächst steht dieses Echo in einem gewissen Widerspruch zur These von dem schwindenden Einfluss der Religion in der Gesellschaft. Doch während bei Frankl Selbsttranszendenz das ist, was jeden Menschen glaubensfähig für die Gotteserfahrung macht, demnach Voraussetzung für Gotteserfahrung ist, gewinnt der Begriff bei Joas eine etwas breitere Bedeutung, die die Gotteserfahrung berühren kann, aber nicht muss. Joas beschreibt, welche Art die Anmutungen sind, die Akte der Selbsttranszendenz ins Bewusstsein treten lassen. Er skizziert das Moment des Erlebens und betont dabei stärker die Ungewöhnlichkeit dieser Erfahrung: „Ich schlage also vor, auf eine Art von Erfahrungen zu reflektieren, die nicht selber schon Gotteserfahrungen darstellen, ohne die wir aber nicht verstehen können, was Glaube, was Religion eigentlich ist. Ich nenne diese Erfahrungen Erfahrungen der Selbsttranszendenz" (Joas, 2004, S. 17).

Es geht dabei um „das Ergriffenwerdens von etwas, das jenseits meiner selbst liegt“, „eines Hinausgerissenwerdens über die Grenzen des eigenen Selbst“. Der Begriff der Selbsttranszendenz taucht im Rezensionsband nicht auf. Vermutlich war das bewusste Absicht der Herausgeber. Doch wenn man diesen beeindruckenden Band mit einer Aura umgeben sieht, die nur von dem geistigen Auge der besonders interessierten Leserschaft wahrgenommen wird, dann drückt diese Aura - so denke ich Selbsttranszendenz aus.

Praktische Theologie und Kirche übernahmen viele Methoden des Pragmatismus stillschweigend. Gott fungiert heute als flexibel handhabbare Größe für eine Bedarfstheologie, die Beratung und soziale Dienste anbietet. Der Begriff „Kirchenkampf“ hat einen neuen Sinn erhalten: Kirchen kämpfen um Mitglieder. Theologen sind besonders gefragt, wenn sie öffentliche Resonanz besitzen. Entsetzen und kollektive Trauer, die ein plötzliches Unglück mit hohen Verlusten an Menschenleben verursacht, werden durch das Gedenken an die Opfer und die Anteilnahme am Schmerz der Hinterbliebenen öffentlich zum Ausdruck gebracht. Die Mitwirkung der Kirchen und Religionsgemeinschaften entspricht dabei einem zentralen gesellschaftlichen Bedürfnis.

William James behielt Recht. Im Vorwort seines Essay-Bandes „The Will to Believe“, Der Wille zum Glauben, machte James (1899, S. XV) deutlich: Im Konkurrenzkampf der Religionen gehe es darum, im Geist von Toleranz die günstigsten Bedingungen für das Überleben des tauglichsten Glaubens zu sichern. 
Die beiden großen christlichen Glaubensrichtungen in Deutschland tun dies, indem sie sich nicht mehr fremd gegenüber stehen, sondern zusammenrücken. Im Vorfeld des Luther-Jubiläums 2017 (500 Jahre Ablassthesen) betont katholischerseits Kardinal Marx, Vorsitzender der deutschen Bischofskonferenz, in Bezug auf die abtrünnigen Protestanten: „Uns eint vieles!“ (Marx, 2016). Der Protestant würde zwar auf Grund einer solchen Versicherung nicht gleich katholisch werden wollen, doch er könnte mit einem Zeichen guten Willens reagieren, indem er das letzte Wort im James Bond-Film „Ein Quantum Trost“ zitiert. Nachdem Geheimdienstchefin „M“ James Bond beschwört, er möge weiterhin im Dienst für Ihre Majestät zur Verfügung stehen, antwortet Bond lakonisch: „Ich war nie weg!“

\section{Literatur}

Alexander, Michelle (2010): The New Jim Crow. Mass Incarceration in the Age of Colorblindness. New York NY: New Press.

Deuser, Hermann; Joas, Hans; Jung, Matthias \& Schlette, Magnus (Eds.) (2016): The Varieties of Transcendence. Pragmatism and the Theory of Religion. New York: Fordham University Press.

Dewey, John (1891): The Collected Works. Ed. by Jo Ann Boydstone. The Early Works [EW], Vol. 3, 18891892. Early essays and Outlines of a Critical Theory of Ethics. Carbondale: Southern Illinois Univ. Press.

Dewey, John (1897): My Pedagogic Creed. URL: http://dewey.pragmatism.org/creed.htm (Abruf: 6.11.2016).

Dewey, John (1906): Experience and Objective Idealism. In: The Collected Works. Ed. by Jo Ann Boydstone. The Middle Works [MW], Volume 3. Carbondale: Southern Illinois Univ. Press, pp. 128144.

Dewey, John (2002): Logik. Theorie der Forschung. Frankfurt a.M.: Suhrkamp (Orig. amerik. 1938).

Dewey, John (2004): Ein allgemeiner Glaube. In: John Dewey: Erfahrung, Erkenntnis und Wert. Hrsg. u. übersetzt von Martin Suhr. Frankfurt a.M.: Suhrkamp, S. 229-292 (Orig. amerik. 1934).

Dewey, John (2016): Kunst als Erfahrung. 8. Aufl. Frankfurt a.M.: Suhrkamp. (amerik. Orignal 1934).

Du Bois, W.E.B. (2008): Die Seelen der Schwarzen - The Souls of Black Folk. Freiburg i. Br.: Orange Press (Orig. amerik. 1903).

Frankl, Viktor (2005): Der leidende Mensch. Anthropologische Grundlagen der Psychotherapie. 3. Aufl. Bern: Huber.

Glaude jr., Eddie S. (2007): A Shade of Blue. Pragmatism and the Politics of Black America. Chicago: University of Chicago Press (insbes. S. 17-46).

Hohr, Hansjörg \& Retter, Hein (2009): Gesellschaft, Religion und Ästhetik in der Erziehungsphilosophie John Deweys. Bad Heilbrunn: Klinkhardt.

Hook, Sidney (1959): Pragmatism and the Tragic Sense of Life. In: Proceedings and Addresses of the American Philosophical Association. Vol. 33 (1959/1960), pp. 5-26. URL: http://www.jstor.org/stable/3129513 (Abruf: 6.11.12016).

James, William (1899): Der Wille zum Glauben und andere popularphilosophische Essays. Stuttgart: Frommann.

James, William (1902): The Varieties of Religious Experience. A Study in Human Nature. URL: www.hudevbooks.com/library/william james var.pdf (Abruf: 6.11.2016).

James, William (1925): Die religiöse Erfahrung in ihrer Mannigfaltigkeit. Materialien und Studien zu einer Psychologie und Pathologie des religiösen Lebens. Übersetzung u. Bearbeitung von Georg Wobbermin. 4. Aufl. Leipzig: Hinrichsche Buchhandlung. 
Jaspers, Karl (1931): Die geistige Situation der Zeit. Berlin: de Gruyter.

Joas, Hans (2004): Braucht der Mensch Religion? Über Erfahrungen der Selbsttranszendenz. Freiburg i.Br.: Herder.

Kegley, Jacquelyn Ann K. (2009): Josiah Royce on Race: Issues in Context. In: The Pluralist, Vol. 4, No. 3, pp. 1-9. URL: http://www.jstor.org/stable/20708988 (Abruf: 6.11.2016).

Kestenbaum, Victor (2002): The Grace and the Severity of the Ideal. John Dewey and the Transcendent. Chicago: University of Chicago Press.

Lewin, Kurt (1931): Die psychologische Situation bei Lohn und Strafe. Leipzig: Hirzel.

Marquard, Odo (1987): Abschied vom Prinzipiellen. Stuttgart: Reclam.

Marx, Reinhard (2016): „Uns eint vieles.“ Interview. In: Chrismon spezial. Das evangelische Magazin. Ausgabe zum Reformationstag am 31. Oktober 2016, S. 19.

Peirce, Charles S. (1965): Collected Papers of Charles Sanders Peirce Vol. V: Pragmatism and Pragmaticism, Vol. VI: Scientific Metaphysics. Ed. by C. Hartshorne and P. Weiss. Two Volumes in One. Cambridge (Mass.): The Belknap Press of Harvard University Press.

Petersen, Peter (1971): Führungslehre des Unterrichts. 10. Aufl. Weinheim: Beltz.

Ralston, Shane (2007): John Dewey „on the side of the angels”. A Critique of Kestenbaum's Phenomenological Reading of „A Common Faith“. In: Education an Culture, Vol. 23, No. 2, p. 63-75. URL: http://www.jstor.org/stable/42922611. (Abruf: 6.11.2016).

Retter, Hein (2017): Faszination und Schwierigkeiten der Sozialphilosophie Deweys. „Nun aber bleiben Glauben, Hoffnung, Demokratie - diese drei.“ In: Konrad, Franz-Michael; Knoll, Michael \& Fuchs, John A. (Hrsg.): John Dewey als Pädagoge. Erziehung - Schule - Unterricht. Bad Heilbrunn: Klinkhardt (in progress).

Rice, Daniel F. (1993): Reinhold Niebuhr and John Dewey. An American Odyssey. Albany, NY: State University of New York.

Royce, Josiah (1908): Race Questions, Provincialism and Other American Problems. Reprint 1967. Freeport, NY: Books for Libraries Press.

Royce, Josiah (1912): The Sources of Religious Insight. New York: Charles Sccribner's Sons.

Royce, Josah (1914): The Problem of Christianity. Vol. 1: The Christian Doctrine of Life. Vol. 2: The Real World and the Christian Ideas. New York: MacMillan.

Rummenie, Bruce (2010): John Dewey and Reinhold Niebuhr. An Uncommon Faith. LAP Lambert Academic Publishing.

Schiller, F.C.S. (1907): Studies in Humanism. London. Macmillan.

Schiller, F.C.S. (1932): Social Decay and Eugenical Reform. London: Constable \& Co.

Slater, Michael R. (2014): Pragmatism and the Philosophy of Religion. Cambridge: Cambridge University Press.

Smith, Thomas V. (1931): The Religious Bearings of a Secular Mind: George Herbert Mead. In: The Journal of Religion, Vol. 12 (1932), No 2, pp. 200-213. URL: http://www.jstor.org/stable/1197002 (Abruf: 6.11.2016).

Tillich, Paul (1926): Die religiöse Lage der Gegenwart. Berlin: Ullstein.

Wundt, Wilhelm (1921): Probleme der Völkerpsychologie. 2. Aufl. Stuttgart: Kröner (Erstauflage Leipzig, 1911).

Zakai, Avinhu (2008): The Irony of American History. Reinhold Niebuhr and the American Experience. In: Revue LISA/LISA e-journal. URL: http://lisa.revues.org/915 (Abruf: 6.11.2016). 


\section{Über den Autor}

Prof. Dr. Hein Retter: Emeritus, Technische Universität Braunschweig, Institut für Erziehungswissenschaft (Deutschland); Website: https://www.tu-braunschweig.de/allgpaed//personal/ehemalige/hretter. Kontakt: h.retter@tu-bs.de

? 9 ?

1 Die Autoren des Bandes sind in der Reihenfolge der Beiträge: Christoph Seibert (Hamburg), Sami Philström (Helsinki), Christian Polke (Hamburg), Victor Kestenbaum (Boston, USA), Matthias Jung (Koblenz), Wayne Proudfoot (New York), Magnus Schlette (Heidelberg), Michael L. Raposa (Bethlehem, Pennsylvania/USA), Gesche Linde (Darmstadt), Vincent Colapietro (Pennsylvania State University), Hans Joas (Berlin), Ludwig Nagl (Wien), Hermann Deuser (Erfurt), Robert C. Neville (Boston, USA). 